Canada is at a "pivotal moment" with respect to medicare.

"There is no question that reform is coming and we have the potential to design the best health system in the world," he says. "It's not a question of debating the pros and cons. It's more about taking the best from what we can learn about systems that work and also learning from the mistakes that other people have made."

Doctors should not only be at the table for that discussion, "we should be at the head of the table," Day adds. "Governments need more help from doctors than they've asked for or have taken in the past."

In a submission to Senator Michael Kirby's committee on health care in 200I, Day recommended repealing the Canada Health Act. "The Canada Health Act achieves the reverse of what it was set out to do. In fact, the people from lower social economic groups, people who do not have the ability to pick up the telephone and make a phone call, people who do not know how to wheel their way around the system are the ones who suffer in a system like this," he said at the time.

Asked if he still supports that view, Day responded that while there is nothing in the Act that is bad, "it has to be updated." - Laura Eggertson, CMAJ

DOI:I0.1503/cmaj.060256

\section{STIs a "hidden epidemic":}

\section{SOGC}

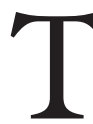

he Society of Obstetricians and Gynaecologists of Canada (SOGC) is calling for a national strategy to combat rising rates of sexually transmitted infections (STIs), which they say have risen so much they constitute a "hidden epidemic."

Cases of chlamydia rose by $74 \%$ from I997 to 2004, states the SOGC, which analyzed data provided by the Public Health Agency of Canada. The incidence rate was I9I.4 per Ioo ooo people in 2004, up from Io9.9 per 100 ooo in 1997.

Gonorrheal infections increased by
$8 \mathrm{I} \%$, with an incidence rate of 26 per IOO 000 in 2004 compared with $\mathrm{I} 4.3$ in I997.

Syphilis rose by $908 \%$ over the same period, with an incidence rate of 3.9 per IOO 000 in 2004, from 0.4 per 100000 in I997. (The 2004 figures were calculated by projecting current case rates as of June 2004 to I2 months.)

Chlamydia was most common in people aged I5 $^{-24}$ and gonorrhea was most prevalent among women I5-24, and men 20-29. Cases of syphilis occurred primarily in men aged 30 and older.

"What we need to have is a national strategy," says SOGC Associate Executive Vice-President Dr. Vyta Senikas.

A multimillion-dollar strategy, consisting of a broad-based public education campaign, should come from "the top," and include Health Canada and the Public Health Agency of Canada as "active partners," as well as non-governmental organizations such as the SOGC, Planned Parenthood, family physicians, nurses and rural physicians, Senikas says.

Physicians believe the infection rates are increasing, in part, because young people are engaging in more unprotected sex and because they believe oral sex is safer than it is, says Senikas.

The Society, which plans to lobby the new Health Minister on this issue, doesn't know how much the campaign would cost.

However, "the consequences of these diseases, the burden of these diseases on the public is enormous," says Senikas. - Laura Eggertson, CMAJ

DOI:10.1503/cmaj.06or5I

\section{Canadian helps WHO}

\section{with pandemic}

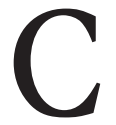

anada's deputy chief public health officer is heading to

Geneva on a 2-year secondment to help the WHO prepare for a possible influenza pandemic.

In April, Dr. Paul Gully will begin working with Dr. Margaret Chan, WHO's pandemic point person and deputy director-general for prevention of communicable diseases. Gully's specific responsibilities had not been defined at press time, although he may be working in the area of rapid response and containment in countries where a pandemic strain of influenza is first detected.

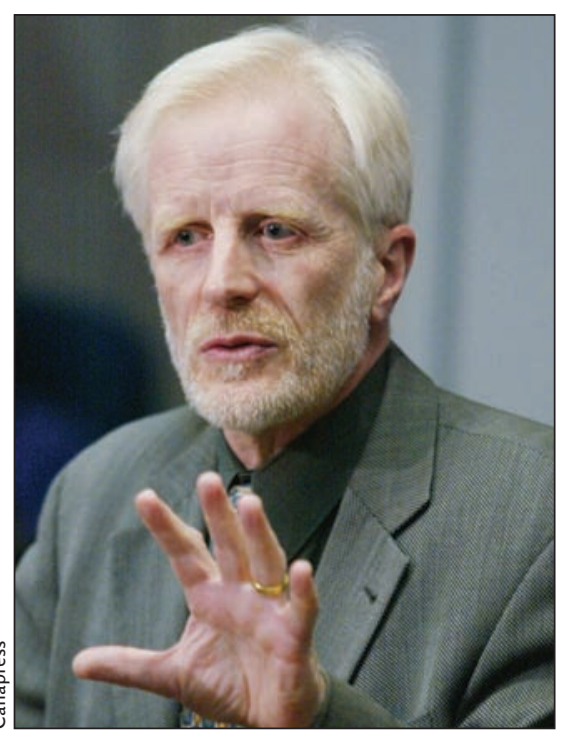

Improving surveillance will be critical, says Gully.

WHO, which has a long-standing working relationship with Canada, asked for Gully specifically, in an arrangement that will also benefit the Public Health Agency, Gully told CMAJ.

"We think that enabling their capacity is very important," says the former senior director general of population and public health at Health Canada. "It's also good for Canada to have someone who knows the Canadian system and is wellversed in the situation here, to be there."

In January, donor countries pledged almost US $\$ 2$ billion toward eradicating the $\mathrm{H}_{5} \mathrm{Nr}$ virus infecting poultry flocks in Asia and Europe. The $\mathrm{H}_{5} \mathrm{NI}$ virus is considered the leading pandemic candidate.

"It will be very important to ensure that the funds are spent in the best way to ensure that the strategies, both from the animal side and from the human health side, are able to be worked on," Gully says. Improving identification and surveillance infrastructure in many countries will be critical, he added. - Laura Eggertson, $C M A J$

DOI:Io.I503/cmaj.060I52 